\title{
Prediction of Children's Referral to Mental Health and Special Education Services from Earlier Adjustment
}

\author{
Hans M. Koot ${ }^{*}$ and Frank C. Verhulst ${ }^{*}$
}

\begin{abstract}
The 4-year stability in problem behaviors assessed with the Child Behavior Che klist (CBCL), and their predictive validity with regard to poor outcome variables was studied in 1052 4-12-year old children from a general population sample. Irrespective of sex and age, the scores on the CBCL of some $44 \%$ of the children remained above the 90 th percentile over the 4-year time interval. Externalizing problem behavior tended to show somewhat greater stability than internalizing problem behavior. High initial levels of boh internalizing ind externalizing problems, and persistence of problems were predictive of referral to mental health services. Referral to special education was higher for younger boys with high initial attention problems and school problems. Police contacts occurred more often in older boys with high initial aggression scores.
\end{abstract}

Keywords: Feferral of children, parent ratings, problem behavior, longitudinal prediction

\section{Introduction}

Information on the stability of problem behavior in children across time is important to assess which early problems predict later psychopathology, to evaluate the necessity and efficacy of prevention and intervention programs, and to assess the validity of diagnostic constructs in terms of outcome. For clinical practice, it may be of particular interest to know whether the children from the general population who are most deviant at the first time of assessment will remain the most deviant or will be those children with the biggest chance of having a poor outcome at the next time of assessment.

A number of prospective studies have investigated the course of problem behaviors in children from the general population using parent and/or teacher reports (Douglas, Ross \& Simpson, 1968; Fischer, Rolf, Hasazi \& Cummings, 1984; Gersten, Langner,

Accepted manuscript received 26 April 1991

*Department of Child Psychiatry, Sophia Children's Hospital, Erasmus University, Rotterdam, The Netherlands.

Requests for reprints to: Hans M. Koot, Sophia Children's Hospital, Department of Child Psychiatry, Gordelweg 160, 3038 GE Rotterdam, The Netherlands. 
Eisenberg, Simcha-Fagan \& McCarthy, 1976; Ghodsian, Fogelman, Lambert \& Tibbenham, 1980; Graham \& Rutter, 1973; Havighurst, Bowman, Liddle, Matthews \& Pierce, 1962; Macfarlane, Allen \& Honzik, 1962; Richman, Stevenson \& Graham, 1982; Ruttcr, Graham, Chadwick \& Yule, 1976; Shepherd, Oppenheim \& Mitchell, 1966; Stevenson, Richman \& Graham, 1985; Verhulst \& Althaus, 1988; Verhulst, Koot \& Berden, 1990a). From these the following general conclusions may be drawn: about $50 \%$ of the deviant children remain deviant $2-5$ years later; externalizing problems are somewhat more stable than internalizing problems; problem behavior seems to be more stable in boys than in girls, especially at young age, but this may be an artifact of the higher prevalence of externalizing behaviors in young boys, which are more stable; bchavior problems become more stable with increasing age; externalizing problems secm somewhat predictive of later school dropout and antisocial behavior.

Most of the existing studies on the stability of problem behavior in children were limited by factors such as the restriction of the sample to a single locality or the use of selected samples; large sample attrition; the use of different assessment instruments at different times; and the use of very broad categories of functioning. In two recent follow-up studies (Verhulst \& Althaus, 1988; Verhulst et al., 1990a) such limitations were not present. Using the Child Behavior Checklist (CBCL; Achenbach \& Edelbrock, 1983) to obtain parents' reports of problem behavior, high stability was found for both internalizing and externalizing problems in a general population sample including more than $80 \%$ of the original subjects. In the only other follow-up study of a general population sample in which the CBCL was used at follow-up but not at initial assessment (Fischer et al., 1984) externalizing problems were more stable than internalizing problems. This study, however, only included preschool children.

In clinical practice it is important to know to what extent particular problems are predictive not only of later problem behavior but also of other indices of maladjustment. Referral to mental health scrvices and to special education scrvices, suicide attempts, police contacts and conflicts with teachers which lead to expulsion from school may be other valid indicators of maladjustment. To our knowledge, however, no study addressed the longitudinal relation between severity of problem behavior and later referral to mental health and special education services. Only a few general population studies addressed the relation between problem behavior and later police contacts (c.g. Farrington, Gallagher, Morley, Ledger \& West, 1986; Pulkkinen, 1988).

In the present study a representative sample of 4-12-year old children from the general population was followed up over a 4-ycar period using parental reports on problems and on other indices of maladjustment. The aims of the study were: (1) to test to what extent the most deviant children at the first time of assessment would remain the most deviant at follow-up; (2) to test to what extent high levels of problem bchavior are predictive of later maladjustment over a 4-year period; (3) to test whether different types of problem behavior have different predictive value with regard to later maladjustment; (4) to test to what extent predictability of maladjustment is related to demographic variables (sex, age, and socioeconomic status); and (5) to explore why some children with problems at the first time of assessment do not come to treatment in mental health or special cducation services. 


\section{Method}

\section{Sulieitis}

The original general population sample of children aged 4 - 16 years was drawn in 1983 from the Duth province of \%uid-Holland. Using municipal birth registers that list all resiofents, a random sample was trawn of 100 children of each sex and age with the Dutch nationality $(N=2600)$. Parents of the selected chidren were interviewed by previously trained intervicwers, and answers were recorded on a mathine readable form. Of the 2447 parents reached, $2076(84.8 \%$ ) provided usable data (set Verhulst, Akkertidis \& Althaus, 1985 a, for more details on the sampling and data collection procedure)

1)ata wexe obtained in 1983 (Time 1), 1983 (Time 2), and 1987 (Tine 3). Fon the present follow-up study (Tine 3), 1464 children were selected who belonged to the age groups $4-12$ years in 1983 , because the parental reports on thildren s problems behaviors are only validated up to the age of 16 years. Parents were intervicwed using the same procedure at Times 1 and 3 . At 'lime 2 data were collected employing a maling survey, resulting in the selective exclusion of a group of especially problematic children. Therefore, in this paper only 'l'imes 1 and 3 data will be reported. Usable data were obtained for 1200 of the 1461 now $8-16$-year old children (581 boys, 619 girls). The response rate was $82.8 \%$, corrected for 10 chithen who were known to have moved abroad and five others who could not be wared. Socioconomic status (SES) was scored on a six-step scale ol occupation as reported by the parent (Vitn Westerlaak, Kropman \& Collaris, 1975). Three SES categories were fomed: (1) unskilled and skilled manual employees; (2) clerical, technicians, minor professionals, and owners of small businesses; (3) supervisory, lesser professionals, executives, major professionals, and owners of large businesses.

\section{Meanites}

Prablem behaior and competence. The CBCI. (Acherbach \& lidelbrock, 1983) was used to obtain standarlized parents' reports of children's problem behavior and compelencies. The: CBCI, is selfexplanatory, enabling most parents or others who know the child well 10 complete it independently in 15-30 minules. Its good reliability and discriminative validity established for American samples were contirned in our own studies (Verhulst et al., 1985a; Verhulst, Berden \& Sanders-Woudstra, $1985 \mathrm{~b}$ ).

The CBCIL consists of 20 competence items and 118 items concerning problem behavior. The conjelene ittms are summed in the following thee scales: Activities scale, Social scale, and School scale. The thece scale scores were s.ummed to give a total competence score as outlined by $A$ chenbach and Edelbrock (1983). The 118 problem items describe a broad range of problems that are of concern to parcnts and clinicians. l'arents are requested to circle a 0 if the item is not true lor the child, a 1 if the item is somerehat on sometimes true, and a 2 if it is very true or oftun tree. A total problem score is calculated by summing 0 s. 1s and $2 \mathrm{~s}$ for those 118 items. The higher the total problem score, the bigher the level of disturtiance of the child.

Achenbath and Edelbrock (1983) have tonstructed empirically derived syndromes by factor analysing parents' ratings of large samples of children referred to mental health agencies. Analyses were performed for both sexes and age groups 4-5, 6-11, and 12-16. For cach sex-and age-group, the authors computed the wo brotd-hand factors Internalizing and Externalizing. For these syndromes an Internatizing score and an Examalizing score were calculated by summing the scores on the items they comprise. The authors Aso calcuated for each sex- and age-group several narrow-band fators. A problem, however, with regand whe analysis of longitudinal data is that the longer the lime interval between two times of assessucht, the more childen will move out of their original age category into a category for which somewhat different syndrome constellations were reported. Therefore, we used so-called "core syndromes" constructed by Achenbach, Conners, Quay, Verhulst and Ifowell (1989). These core syndromes consisted of iterns that were common to most syndromes across different sex/age groups. 'They were terived by factor analysis on four sets of parents' ratings of 81946 -16-year olds referred to American and Dutch mental health services. The names of these core syndromes summarize the items comprising cach of the scales. There are seven core syndromes across both sexes and ages 6-16: Asuressive, Anxious/Depressed, Attention Problem, Delinquent, Schizoid, Somatic Complaints, and Withdraun. Oue syndrome, Socially Inefl, was found only for boys, while another, Mean, was found only for girls. A score for axh of these syndromes was calculated by summing the scores of the items they comprise. 
Outcome. At Times 2 and 3 the parents' reports about the occurrence of one or more of the following items were obtained: (a) referral to mental health services; referral to residential school or home for psychosocial reasons; (b) referral to special education services (excluding counscling for choice of secondary school level); (c) trouble with the police (arrest or adjudication, excluding traffic violations) or expulsion from school. If an item applied to the child in the period between Times 1 and 3 the item was scored as prescnt. Subjects for whom such information was not available over the first 2 ycars of the study were excluded from the analysis on outcome variables; i.e. these analyses werc done on 1052 of the 1200 subjects.

\section{Results}

\section{Stability and change}

Categories were formed of children scoring in the low, medium, or high range of the total problem score, of the broad-band syndromes Internalizing and Externalizing, and of the scores on the core syndromes Aggressive, Attention Problems, Anxious/Depressed, and Withdrawn at Times 1 and 3. The 50th and 90th percentiles for each sex and age group of the cumulative frequency distributions of the total problem and syndrome scores were chosen as cut-off points. It was not possible to determine similar cut-off points for the syndromes Delinquent, Schizoid and Somatic Complaints.

Table 1. Distribution (\%) of total problem score group at Time 3 by total problem score group at Time 1

\begin{tabular}{lccc}
\hline & \multicolumn{3}{c}{ Time 3 group } \\
\cline { 2 - 4 } Time 1 & & & \\
group & Low & Medium & High \\
\hline Low & 72.9 & 25.2 & 1.8 \\
& $(439)^{\text {a }}$ & $(152)$ & $(11)$ \\
Medium & 35.4 & 53.7 & 10.9 \\
& $(168)$ & $(255)$ & $(52)$ \\
High & 4.9 & 50.8 & 44.3 \\
& $(6)$ & $(62)$ & $(54)$ \\
\hline
\end{tabular}

"Figures in parentheses are actual numbers of children in each group.

As can be seen from Table 1, 44\% of the children who scored above the 90th percentile at Time 1 obtained scores in the same range 4 years later. Of the remaining $56 \%$ of the children scoring above the 90 th percentile only $5 \%$ moved into the group scoring in the bottom $50 \% 4$ years later. Highest stability was found for children scoring below the 50 th percentile at Time 1 . Almost three-quarters of them remained in the same category, while only $1.8 \%$ scored above the 90 th percentile at a later age. The proportion of children remaining in the same category and of those changing 
to other categories was not significantly affected by sex and age. Similar 4-year stabilities were found for the core syndrome scores using the same cut-off points. The percentages of children persistently scoring above the 90 th percentile across the 4-year interval wore: Internalizing, 38; Externalizing, 48; Aggressive, 53; Attention Problems, 46; Anxious/Depressed, 41; and Withdrawn, 34. No significant sex or age differences in the stability of syndrome scores were found. It may be concluded that overall one-third to one-half of the children show stable problem behavior over a 4 -year interval.

\section{Prediction of outcome}

Next, the relationship between Time 1 predictor variables and the outcome variables obtained over the 4-year interval was analysed. For these analyses referral to mental health services, referral to residential school/home, and scores on the CBCL item "Deliberately harms self or attempts suicide" were combined. Likewise, trouble with police/justice and expulsion from school were joined to form one variable.

In this general population sample $6.0 \%$ of the children were referred at least once in the 4-ycar interval to mental health services, $6.7 \%$ were referred to special education services, while $1.9 \%$ were in trouble with the police. In Table 2 the distribution of outcome variables by demographic and problem variables is given. All predictor variables, except SES, were dichotomized. Chi-square tests on the distributions of outcome variables by sex, age, SES and lime 1 low and high scoring problem groups were all highly significant $(p<.001$; except SES, $p<.05)$, indicating effects of these variables on the referral rates. Chi-square tests on distributions of outcome variables by the activitics and school scale scores were slightly significant $(p<.05)$, whereas the total competence and the social scale scores were not significantly related to outcomes. The distributions were informative with regard to the exact percentages of children from each predictor category who scored on one or more of the outcome variables. For example, $33.9 \%$ of the children scoring above the 90 th percentile of the CBCL, total problem score were at least once referred to any services or had had trouble with the police during the 4-year interval, versus $12.3 \%$ of the children scoring in the lower range.

Becaust the various CBCL scores are not independent from each other nor from the demographic variables mentioned above, stepzise logistic regression analyses were performed with three different sets of predictors. "The first set included sex, age, SES, the $\mathrm{GBCL}$ total problem score, and the CBCL total competence score. The second included sex, age, SES and the broad-band syndromes Internalizing and Externalizing and the GBCI. total competence score. The third set included sex, age, SES, the syndrome scales Aggressive, Attention Problems, Anxious/Depressed and Withdrawn, and the competence scales Activities, Social and School. Separate sets were used because results with all bchavior problem scores included in one set would be blurred by the overlap of the items constituting the different scores.

Logistic regression is used with dichotomous outcomes to evaluate the predictive value of a set of independent variables. For the independent variables, the strength of association is evaluated using relative odds (the odds ratio, OR). Relative odds in logistic regression analyses assess the unique contribution, i.e. separate from the 
Table 2. Distribution of outcome variables over the 4-year interval by demographic variables and levels of problem behavior and competence at Time 1

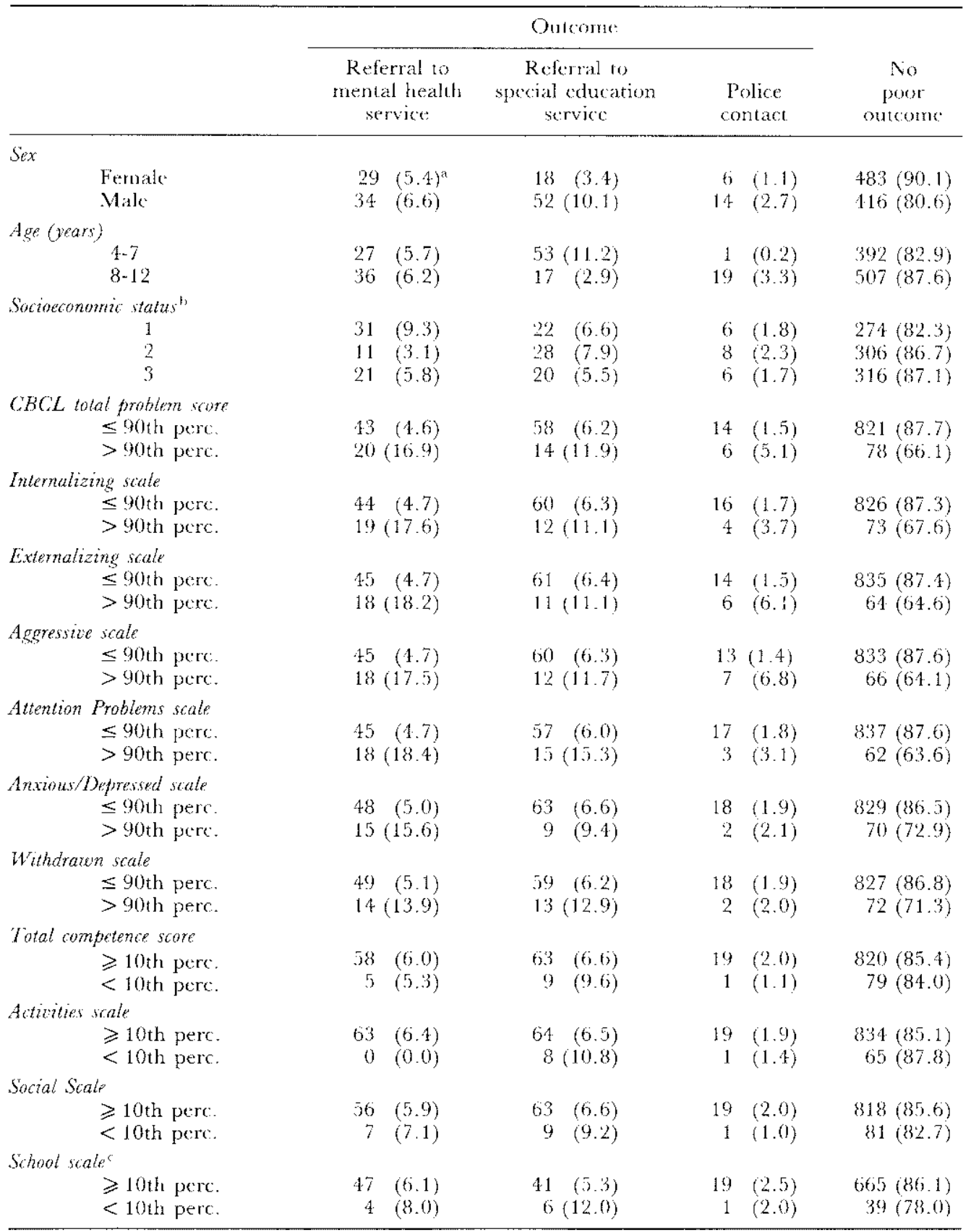

"Row percentages in parentheses.

Three missing values.

"Not for 4-5-year olds. 
other variables in the model, made by each independent variable to the prediction of outcome. Values greater than 1.0 indicate a positive relation with outcome; values less thar 1.0 indicate a negative relation with outcome. The BMDP program PLR (Dixon, 1983) was used with the statistical criterion for factor entry set at $p<.10$. In Table 3 an OR is presented only when the $95 \%$ confidence interval around it excluded 1.0. Since the ORs obtained for sex, age and SES hardly differed across the three analyses, only those obtained in the analysis with predictor set 1 are given in this table.

Table 3. Relative odds on stepwise logistic regression of predictor variables against outcome variables

\begin{tabular}{|c|c|c|c|c|}
\hline \multirow[b]{2}{*}{ Predictor variable } & \multicolumn{3}{|c|}{ Outcome } & \multirow[b]{2}{*}{$\begin{array}{c}\text { Any } \\
\text { poor } \\
\text { outcome }\end{array}$} \\
\hline & $\begin{array}{l}\text { Referral to } \\
\text { mental hecalth } \\
\text { service }\end{array}$ & $\begin{array}{l}\text { Referral to } \\
\text { special education } \\
\text { service }\end{array}$ & $\begin{array}{l}\text { Police } \\
\text { contact }\end{array}$ & \\
\hline Sex & - & 3.3 & 2.4 & 2.2 \\
\hline Age group & - & $4.4^{\mathrm{b}}$ & 16.1 & $1.5^{\mathrm{b}}$ \\
\hline Socioeconomic status & 1.4 & - & - & - \\
\hline CBCl, total problem score & 5.0 & 2.1 & 3.4 & 3.7 \\
\hline Internalizing scale & 3.3 & 2.0 & - & 2.2 \\
\hline Externatizing scale & 2.7 & - & 4.4 & 2.8 \\
\hline Aggressive scale & 2.9 & - & 5.1 & 2.7 \\
\hline Attention Problems scale & 3.0 & 2.2 & - & 2.5 \\
\hline Anxious/Depressed scale & - & - & - & -- \\
\hline Withdrawn scale & - & -- & - & 1.8 \\
\hline School scale & - & 4.4 & - & -. \\
\hline
\end{tabular}

(Only predictor variables with at least one significant relation to outcome are listed.

'Younger age group had higher likelihood of outcome.

Analyses involving predictor set 1 showed that boys had a significantly greater risk than girls of being referred to special education scrvices $(\mathrm{OR}=3.3)$ and of getting into trouble with the police $(\mathrm{OR}=2.4$ ). Children from the younger age group had a significantly higher risk of referral to special education services $(O R=4.4)$, whercas, those from the older age group had a much larger likclihood of getting into contact with the police $(\mathrm{OR}=16.1)$. Coming from a lower socioeconomic background was slightly associated with an increased risk of referral to mental health services (1.4). Having a CBCL total problem score above the 90th percentile was associated with a significantly greater risk of referral to mental health services $(O R=5.0)$, referral to special education services $(O R=2.1)$ and contact with the police $(O R=3.4)$. Having a score below the 10th percentile of the total competence score was not significantly associated with a higher risk for any of the outcome variables.

In the analysis with predictor set 2 it was found that having an Internalizing scale scorc above the 90th percentile was associated significantly with referral to both mental health services $(O R=3.3)$ and special education services $(O R=2.7)$, while a score in that range on the Externalizing scale predicted referral to mental health services 
$(\mathrm{OR}=2.4)$ and trouble with the police $(\mathrm{OR}=4.4)$, but not referral to special education services, to a significant degree.

The analyses using the third set of predictor variables showed that having a score above the 90th percentile of the Aggressive scale was associated with a greater likelihood of being referred to mental health services $(\mathrm{OR}=2.9)$ as well as of getting into contact with the police (OR =5.1). A score above the 90th percentile on the Attention Problems scale was indicative of a greater probability of being referred to both kinds of services $(\mathrm{OR}=3.0$ and 2.2, respectively). Finally, having school problems, as indicated by a score below the 10th percentile on the School scale, was associated with a higher risk of referral to special education services $(\mathrm{OR}=4.4)$. No other syndrome scale significantly increased the likclihood of any of the outcomes. Thus, boys and girls of any age between 4 and 12 from the low socioeconomic status groups showing extcrnalizing (aggressive or attention related) and/or internalizing problem behaviors at one point in time will be more often referred to mental health services than other children in subsequent years. Boys in the age range 4-7 years having attention problems, internalizing problems and/or school problems are most likely to be referred to special education services across a 4-year time-span. Boys in the higher grades of elementary school age showing externalizing, in particular aggressive, behaviors have the largest risk of getting into contact with the police and of being cxpelled from school in subsequent years.

Finally, we explored why some initially deviant children were referred during the subsequent 4-year period while other deviant children were not. Of the group of children with Time 1 total problem scores above the 90th percentile $(n=118), 20$ were referred to mental health services, 14 were referred to special education services, and 78 were not referred. The mean total problem score of the deviant group referred to mental health services did not differ from the scores of the non-referred group with deviant scores at Time 1 (59.1 vs 53.7). In contrast, the total problem score of both groups did differ significantly at Time $3(52.6$ vs $35.7, t=3.09, p=.005)$. Further, the initially deviant referred children had significantly higher Time 3 (but not Time 1) mean scores than the initially deviant non-referred children on the aggressive, attention problems, anxious/depressed, somatic complaints and schizoid scales $(p<.05)$. Thus, while the non-referred deviant group showed a considerable decline in problem behavior over the 4-year period (total problem score from 53.7 to 35.7 ), this was not the case for the deviant referred group (mean scores 59.1 at Time 1 and 52.6 at Time 3), despite the services they receive or had received. This absence of a decline of problem behavior seems to be indicative of the presence of more serious and persistent behavior problems in the referred deviant group as compared to the non-referred deviant group.

\section{Discussion}

The present 4-year follow-up of problem behavior in a sample of 1200 children from the general population originally aged 4-12 revealed high stability in the level of CBCI problem scores. Nearly half of the children who scored in the high range of the total problem scores at the first time of measurement still scored in this range 
1 years later. It appeared that of the children who initially scored in the high rangt: of aggressive bchavior, attention problems, anxious/depressed and withdrawn behavior, $53,46,41$, and $34 \%$, respectively, scored in the same high range 4 years later. No sex or age differences in stability were found. This indicates that, irrespective of the child's original age (ranging from 4 to 12 ) and sex, the persistence of externalizing as well as internalizing problem behavior is substantial across a 4 -yeat time interval. This is in agreement with the high stability of problem behaviors found in previous studies for preschool children (Richman ef al., 1982) as well as young adolescents (Graham \& Rutter, 1973; Rutter of al. 1976). This study, however, as far as we know is the first 10 present longitudinal data of the stability ol problem behavior and its relation to poor outcome in a general population sample coveting preschool to adolescene, assessed with the same instruments and following the same methodology.

The stability for aggressive behavior agrees with findings from other investigations (Locber, 1982; Olweus, 1979) and indicates that aggressive behaviors in children at one age, cven in young children, strongly predict aggressive behaviors some years late.

The results from the logistic regression analyses showed that scoring in the highest range of the total problem score at lime 1 was particularly predictive of mental health referral and getting into rouble with the police, but much less of referral to special education services. Scale scores appeared to be most revealing in this respect. Whil having a score above the 90 th percentile for either aggressive behavior or attention problems or both was predictive of referral to mental health services, only sorring high on atumtion problems was predictive of referral to special education services, and only scoring high on aggressive was indicative of getting into trouble with the police. Scoring low on the competene part of the CBCI did not seem to be of particular value in the prediction of poor outcome variables. Only the School scale appeared to be indicative of relerral to special education services. Also the demographic variables secmed to have an impact on the chance of having a poor outcome in the subsequent years. Being a boy increased the risk of being referred to special education services as well as getting into trouble with the police, but did not affect the chance of being referred to a mental health service. Being in the age range of $4-7$ increased the risk of referal to special education services, and belonging to the age group $8-12$ years increased the risk of police contact. However, childen from both age groups had equal chances of getting referred to mental bealth services. Socioeconomic status appeared to be prediceive only of referral to mental health services. Children from the lowest sociocconomic status groups had a somewhat higher risk of referral.

These lindings suggest that especially problems which are vexing, intense, and persistent form important reasons for adults to seek help for the child. Persistence of problen behavior scems to be of special importance with regard to referral to mental health services, since of the children with initially high lovels of problem bethavin only those whose levels remained high had been referred to those services. Particularly, aggressive behavior and attention problems appeared predictive of a poor outcome. The findings indicate that socially less well accepted and generally disturbing behaviors tended to persist more stongly than specific problems rellecting inner conflict tapped by the syndromes Anxious/Depressed and Withdrawn. However, it should be stressed that the presence of internalizing problems and externalizing problems secm to be equally important reasons to seek professional help. 
Other studies found a relation between referral status and the severity of parent reported problem behavior in their children, in particular antisocial behavior (Garralda \& Bailcy, 1988; I angner et al., 1974; Wolff, 1976), as well as between relerral status and parental concern about the ability to control the children and the high stress felt about them (Garralda \& Bailey, 1988; Bailey \& Garralda, 1989). We found a significant contribution of the broad-band Internalizing scale scores to the prediction of referrals. It is of interest that internalizing scores increased the risk for referral to mental health services as well as spccial education services to a greater extent than did scores on the externalizing scalc. This effect of internalizing behavior on outcome is independent of the effects of other predictor variables, because these were partialled out in the analyses. Apparently, not only externalizing problems but also internalizing problems may cause substantial distress to the environment so that adults become aware that internalizing problems cause suffering to the child.

This study confirms findings from previous, cross-sectional studies (e.g. Offord et al., 1987) which showed that the majority of children with problem behaviors in the general population remain untreated. Only $16.9 \%$ of the children in the present study with initial high problem scores were referred to mental health services during the follow-up period. Several explanations may be provided for this low rate of service utilization. First, there is the possibility that children's problem behaviors are transitory and that the need for intervention disappears. Our findings partially rule out this possibility: for $44 \%$ of the initially high scoring children the problem scores remained within the highest decile and for another $51 \%$ the scores remained above the median. Second, there are a number of factors in the process of referral that may interfere with the child receiving adequate help, including (1) parental failure to perceive their child's problem, (2) the reluctance of parents who do perceive a problem to seek help, (3) Cailure of primary health care professionals to identify mental health problems, (4) reluctance of these professionals to refer a child to a mental health service, and (5) inaccessibility or unavailability of specialized services (for a detailed description of the referral pathway to child psychiatric help, see Verhulst \& Koor, 1991). Lack of access to or unavalability of mental health services or cost to the child's parents do not provide a plausible explanation, because for lower and middle income groups in the Netherlands at the time of the study these services were payed for by obligatory insurance. 'This study provides no information on the other possible explanations. However, it does give information on the value of the CBCL as a screcning instrument to be used for intervention in primary health care. Many parents who are concerned about behavioral, emotional and developmental problems do not discuss these issues with the primary health care protessional (Hickson, Altmeier \& O'Connor, 1983). Discussion of parental concerns about their children's problem behavior, however, increases the likelihood that primary health care professionals will identify psychopathology (Dulcan et al., 1990). Used as a screening instrument, the CBCL may enchance the parents' as well as the primary health care professionals' sensitivity to behavioral deviance. As shown in this study, the instrument is fairly sensitive to persisting behavioral and emotional problems, while in other studies (e.g. Achenbach \& Edelbrock, 1983; Verhulst et al., 1985a,b; Verhulst, Versluis-den Bieman, van der Fnde, Berden \& Sanders-Woudstra, 1990b) it has been shown to discriminate well between disturbed and non-disturbed children and to be correlated with clinical 
severity ratings. However, it should be noted that selection of problem children only based on the cut-off scores provided with the CBCiL will also yield a significant number of false positives. Therefore, in accordance with the multiaxial assessmem approach proposed by Achenbach (Achenbach \& McConaughy, 1987) reports on the child's problem behavior should be obtained from multiple informants, including parents, teachers and children themselves.

This study did not consider other factors which may affect adults' tendency to sect help, and thus be additive to the predictive power of problem behaviors in this regard. Broken homes, unstable fanily circumstances and parental problems may not only be related to the onset (c.g. Rae-Crant, Thomas, Offord \& Boyle, 1989) and to the persistence of psychiatric disorders (e.g. Cohen \& Brook, 1987), but also act as a catalyst in the parents' readiness to scek help for the child's problems. However, a German study (Esser, Lahnert \& Schmidt, 1986) found that scverity of psychiatric disorder had the best predictive value with regard to the utilization of child psychiatric/psychological treatment facilitics by children aged 8-13, while variables such as adverse family circumstances and loss of the biological parent explained only a relatively small amount of its variance. Also, the jssue of the pervasiveness of problems as a risk lactor was not tested, although some evidence exists that parents and teachers" checklists used together provide the best prediction of special education placement (Mattison, Humphrey, Kales \& Wallace, 1986).

Aknowledgements ... This rescarch was supported by the Sophia lioundation for Medical Researth. and by the Ilealin Research Promotion Programme (SCO).

\section{References}

Actenbad, T. M., Gonners, I. K., Quay, II. C.. Verhulst, F. C. \& Howell, (2. 1) (1989) Replication of enpirically derived syndromes as the basis for taxomomy of childadolescent psychopatholus? Journat of Abnomal Child P'syhology' 17, 299-323.

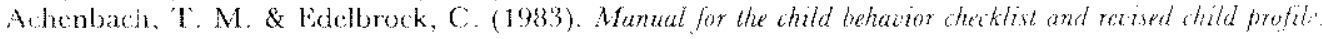
Burlington. VT: Department of Psychiatry, Linversity of Vermont.

Actenbach. I. M. \& MoConaughy, S. H. (1987). Empirirally-tated assessment of dhild and adolosent poychofathology: practical implications. Newbury lark, CA: Sitge.

Batcy, 1) \& Carralda, M. E. (1989). Referral to child psychiatry parent ard todor mundes and expectalions. Joumal of Child Psychlogy and Psychiatry, 30, $449-458$.

Cishen. P. \& Brook, J. (1987). Family factors related to the persistence of psychopathology in child hood and adolescence. Psychiatr, 50, 332-345.

1)ixon, W. J. (Fa.) (1983). B.MDP statistical softuare. Berkeley: University of California Press.

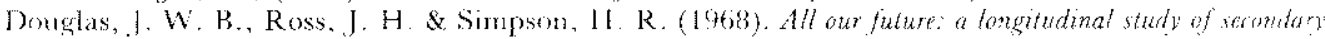
aducation. Tondon: Davies.

Dulan, M. K., Costello, li. J., Costello, A. J., Edelbrock, C.. Brent, J). \& Jiniszewski, S. (19)(n).

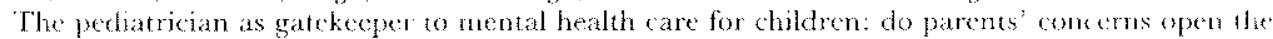
Gate? Jotemal of the American Acatemy of Child and Adoleswe Psychatry, 29, 458-458

Fisser, G, Lahnert, B. \& Schmidt, M. 11. (1986). |Determinants of the utilization al child psychatric/psychological treatment and its sucess.| Keitschrift für Kinderund Jugendpswhiatric, 14. $223-131$.

Farrington, D. P., Gallagher, B., Morkey, 1.. I aclget, R. J. \& West, D. J. (1986). Unemployment, schonl leaving, and crime. British Jounal of Criminolow2. 26, 335-356. 
Fiselser, M., Rolf. J. E. Hasazi, J. \& Cummings, L. (1984). l'ollow-up of a preschool cpidemiological sample: crosi-age continuities and predictions of later adjust ment with internalizing and exterralizing dimensions of behavior. Child l)efopment, 55, 137-150.

Garralda, M. li. \& Bailey, D. (1988). Child and family factors associated with relemal to child psychiatrists. British foumat of Psyctiatry, 153,81-89.

Gersten, J. C. Langner, T. S. Eisenberg, J C, Simcha Fagen, O. \& MeCarthy, E. D. (1976). Stability

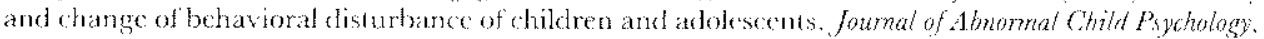
$4,111-127$.

Ghodsian, M., Fogelman, K.. Isambert. L. \& 'Jiblenham. A. (1980). Changes in behavior ratings of a national sample of children. British Joumal of Social and Clintiat Porholegy, 19, 247-256

Grahan, P. \& Rutter. M. (1973). Psychatric disorder in the young adolescent: a follow-up slatly Procedings of the Royal Sictety of Medicine, 66, 1226-1229

Havighurst, R. J., Bowman, P. H., Iiddle, G. P., Matthews, C. V. \& Picree, J. V. (1962). (armang up in River City. New York: Wiley.

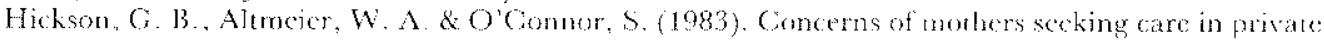
pediatric offices. Pediatrics, 72,619

l.angner, T. S., Gersien. J. C., Greene, E. L. Histrberg, J. (x., Herson, J. II. \& . Carthy, E. D).

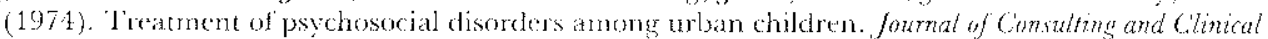
Psychologlt, 42, 170-179.

Ioxber, R. (1982). The stability of antsocial and delinquent child behavior: a review. Child Doweloment: $53,14: 31-1446$

Mactarlane, J. W., Allen. I., \& Honzik, M. I. (1962). A developmental sudy of the behactio problems of normal children beteecn twenty-one monthe and fourten years. Berkeley, CA: Iniversity of Calitorriat Press.

Mattison, R. F., Humphrey, F. J., II. Kales, S. N. \& Wallace, D. J. (1986). An objective evaluation of special class placement of elementary schooltoys with behasior problems. Jonmal of Abmomal Child Pychologs; 14, 251-262.

Offord, D. R., Boyle, M. H., Sxatmari, P., Rae-Grant, N. 1., I inks, P. S., Cadman, 1). 'T'., Byles, J. A. Crawford, J. W., Mumroe Blum, H., Byrne, C, Thomas, H. \& Woodward, C. A. (1987). Ontario Child Health Study. Il. Six-month prevalence of disorder and rates of service utilization. Arhices of General Psychiatry, 44, 832-836.

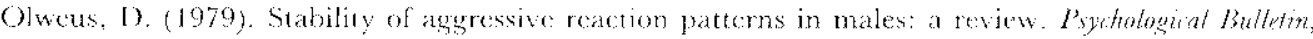
$86,852-8375$

Pulkkinen, 1. (1988). Delinquent development: theoretical and cmpirical considerations. In M. Ruter (lid.). Studies of prychosociat rive: the poese of longitudinal data. Cambridge: Cambridge University Press.

Rae-Grant. N., Thonlits, B. H., Offord, D. R. \& Boyle, M. (1989). Risk, protective factors, and prevalence of thehavoral and emotional disordess in thildren and adelescerns. Joumal of the American Araderny of Child and Adolescent Psychiatry, 28, 262-268.

Richman, V., Stevenson, J. \& Graham, P. J. (1982). Pre-school to scheot: a behavinural sady. London: Acaclemic Press

Ruter, M. Gratharn, P., Chatwick, O. F. 1). \& Yule, W. (1976). Adolescent turmoil: tact or fiction?" Journal of Child Pychology and Psychiatry. 17, 35-56.

Shepherd, M.. (Oppenhein, A. N. \& Mitchell, S. (1966). Childhood behaviour disorders and the childgublance clinit: an epidemiological study. Joumal of Child Psychology and Psyhiatr, 7, 39-52.

Steventon, J., Richman, N. \& Graham, P. (1985). Behaviour problerus and language abilities at threc years and bethavoural deviance at eight years. Joumal of Child Psychology and Pychiatry, 26, 215-230.

Van Westerlatk, J. V., Kropman, J. A. \& Collaris, J. W. M. (1975). Beroptenklapper . Vijnegen: Instituut vour locegepaste Sociolegice

Verhulst, E. C., Akkerhuis, G. W. A Athaus, M. (1985a). Mernal healuh in Dutch chiklen. I. A cross-culturat comparison. Acta Pychiatrica Scandinamia, 72, Suppl. Vo. 323.

Verhulst, I. C. \& Althaus, M. (1988). Persistence and dhange in behaviorat/emotional problems reported by parents of children aged 1-14: an epidemiological study. Acta Psychatrica Scamdinavica, 77, Suppl. No. 339

Verbulst, F. G., Berden, G. F. M. G. \& Sanders-Woudstra, J. A. R. (1985b). Mental healh in Dutch children. I1, The prevalene of psychatric clisorder and relationship between measures. Acte Pouthatrina Sandinaziat, 72, Suppl. No. 324 


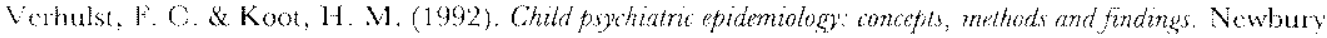
Park, CA: Sage.

Vethukt F. C.. Koot, 11. M. \& Bertern, G. F. M. G. (1990a). Four year follow up of problem beharior

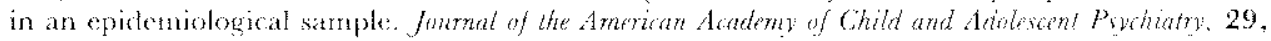
$4.40-48$.

Verhulst, I. C., Verstuis-den Bieman, H. van der Ende. I., Berden, G. F. M. G. \& Sanders-Woudstra, J. A. R. (1990b). Problem behavior in international adoptees. III, Diagnosis of ahild psyebiatice disorthers. Joumal of the American Acadeny of Child and Adolescent Pswchiatry, 29, 420-428.

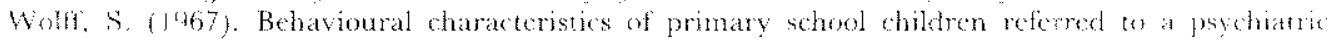
departmern. Britrish Joumai of Psy thatry, 113,8383-893. 
This document is a scanned copy of a printed document. No warranty is given about the accuracy of the copy. Users should refer to the original published version of the material. 